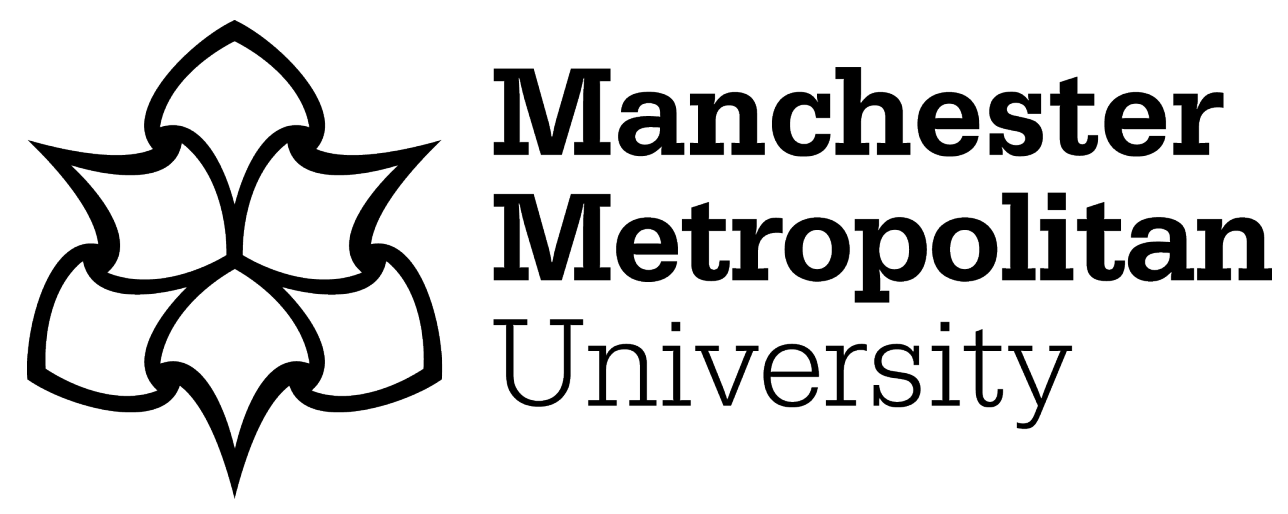

Mainwaring, S and Skinner, H (2009) Reaching donors: neuro-linguistic programming implications for effective charity marketing communications. The Marketing Review, 9 (3). pp. 231-242. ISSN 1469-347X

Downloaded from: https://e-space.mmu.ac.uk/621228/

Version: Accepted Version

Publisher: Westburn Publishers

DOI: https://doi.org/10.1362/146934709X467785

Please cite the published version 


\title{
Reaching donors: neuro-linguistic programming implications for effective charity marketing communications
}

\author{
Susan Mainwaring, Noah's Ark Appeal, Children's Hospital for \\ Wales, UK \\ Heather Skinner, Glamorgan Business School, UK*
}

\begin{abstract}
Proponents of neuro-linguistic programming claim that individuals process the world through preferred sensory representation systems. In other words, we each internally represent the external world through our senses i.e. visual people "see" the world, kinaesthetics "feel" the world, and auditory people "hear" the world. Although there is some limited research into the field of neuro-linguistic programming, particularly that relating to sensory representation systems and marketing communications, this is the first empirical study to investigate the impact of neuro-linguistic programming on charity marketing communications. Our findings reveal that the choices individuals make when exposed to such communications are sensory-based. Although UK charities spend vast sums on main broadcast and press advertising, much of this spend may be wasted as these messages may be filtered out by target market segments. Insights gained from this research may help charities to either ensure their messages reach each potential donor within current target segments, or by further segmenting potential donors by their preferred sensory representation systems, thereby being able to target any direct communications more effectively.
\end{abstract}

Keywords Neuro-linguistic programming, Sensory representation systems, Charities, Marketing communications, Segmentation.

\section{Introduction}

When examining the use of commercial practices such as branding by non profit organisations, Stride (2006) believes that such practices can be both appropriate and effective when utilising a mirror metaphor "to demonstrate how the values with which consumers identify or to which they aspire are 'mirrored' back to them via the brand image" (p. 119). Authors writing about the effectiveness of Neuro-Linguistic Programming (NLP) also discuss the mirroring principle, proposing that people are most likely to respond positively to communications that are presented to them using language (verbal or non-verbal) that mirrors their own representational system (O'Connor and Prior 1995). UK charities spent $£ 59$ million on main broadcast and press advertising in 2004 (Mintel 2006). However, fragmented communications channels, high volumes of marketing communications clutter, and a growing tendency towards advertising avoidance means that much of this spend may be wasted (Croft 1999) as these messages are filtered out by potential donors. This paper rests upon the proposition that neuro-linguistic programming can offer practical insights into the filtering process through an understanding of sensory representation systems that can aid marketers to better target more effective communications messages to potential donors.

\section{$N L P$ research into sensory representation systems}

Neuro-linguistic programming is the name given by its founders, Richard Bandler and John Grinder (1973) to the model and principles they proposed to describe the relationship between mind (neuro), language (linguistic - both non verbal and verbal) and behaviour (programming). NLP has been used in a wide range of business contexts in which it can be seen to be applied to people management and motivation, sales and customer service (Nancarrow and Penn 1998; Yemm 2006), quality management (Ashok and Santhakumar 2002). Its application has also been investigated by American trial lawyers (Carter 2001). However, as pointed out by Skinner and Stephens (2003, p.182) "there is limited academic research into either sensory representation systems or the application of neuro-linguistic programming to marketing". Proponents of NLP believe that individuals process information by using filters or representational systems that produce a map of reality (Dilts 1999; Knight 2004). Skinner and Stephens (2003, p.180) explain that "individuals process each and every encounter with the external environment using sensory representations (pictures, sounds, feelings)". The three basic representational systems are: visual, auditory and kinaesthetic and our 
experiences are represented within one of these contexts; i.e. visual people "see" the world, auditory processors "hear" it and kinaesthetics "feel" it. Yemm (2006) believes that NLP can be most effective in organisations that use such techniques to help improve rapport and communications between sellers and buyers through matching and mirroring. Nancarrow and Penn $(1998, p .14)$ believe that using the customer's language will "translate the features and benefits of your product for him in a way he is most comfortable". An even stronger claim is made by Skinner and Stephens (2003, p. 189):

unless those responsible for forming marketing communications are aware of the sensory language naturally preferred by their target market segments, advertising wastage will be unavoidable, communications may not be able to cut through increasing noise and clutter and a valuable tool for aiding effective communications is not being considered

Nancarrow and Penn (1998) found that it was difficult to conclude whether individual preferred sensory representation systems could be determined over the telephone, but argued that "with the increased interest in one-toone marketing, it is clear that communications on the telephone might be tailored to individual customers as well as products and services" (p. 18). Hence, learning to communicate using the preferred sensory language of target markets may therefore give a competitive edge in a market where resources are limited for the majority of charitable organisations. However, research into the impact of NLP on marketing communications remains very limited and no previous research into NLP and the impact of preferred sensory representational systems on charity marketing communications has been undertaken.

\section{Sensory representation systems: noise and clutter or valid segmentation variable?}

Communications research originally suggested that a linear relationship between sender and receiver took place (Schramm 1948) with the receiver coding the information into symbols that the receiver could decode, with the assumption being that the receiver had knowledge and understanding of the information. Contemporary authors criticise the linear model for assuming that the recipient is merely a passive information processor. Hackley and Kitchen (1998, p. 230) assert that theory has moved "towards a theoretical perspective which conceives communication as a process which is socially mediated and concerns the construction of meaning". Developed models, such as that proposed by Schramm (1971) recognise the "importance of understanding the fields of experience of both the message sender and the message recipient" (Skinner and Stephens 2003, p. 178) and those by authors such as Deetz (1992) and Mantovani (1996), allowing "for more emphasis on two-way, interactive communications rather than a linear process" (Skinnerand Stephens 2003, p. 178).

However, all these models concur that there are a number of factors that may cause a message to go un-noticed by a recipient. Key factors are "noise" where a recipient misses the message due to an external influence, and the "clutter" of the sheer number of marketing communications messages bombarding today's consumers, with Lasn (1999) estimating that consumers are exposed to 3,000 advertisements each day. Hibbert (2005) asserts that competitive pressures on charities drove them to even stronger forms of persuasion resulting in "huge growth in advertising, direct marketing and face to- face requests" (p. 7) that have bombarded the consumer and caused them to be stressed in the face of so many choices of causes, resulting in decisions not to give. Hibbert (2005) suggests that the reason why disaster appeals are so successful is that potential donors are able to focus on a single appeal making the decision to give much easier. As consumers become desensitised to familiar communications stimuli (Shimp 2000) one effective method of cutting through the noise and clutter in advertising is the use of shock (Fill 2002). Although shock can derive from the marketing of "unmentionable.....products, services or concepts that for reasons of delicacy, decency, morality or even fear, tend to elicit feelings of distaste, disgust, offence or outrage when mentioned or when openly presented" "Wilson and West 1981, p. 92), shock is also used to communicate messages concerning more "mentionable" products and services when promoted in an "unmentionable" manner (Wilson and West 1995). "Shocking" advertisements appear to be considered more acceptable by consumers when advertising the work of a charity (Wilson and West 1995) than when used by forprofit consumer goods and services such as Benetton, Calvin Klein, Guinness, Levi and Pepe jeans (Rees 1995).

Additionally, Fill (2002) refers to other cognitive factors that may prevent a recipient perceiving a message. That consumers construct personal meanings though social context is the basis of social constructionist theory, and this seems aligned with NLP where it is argued consumers consciously or 
unconsciously use filters to process information (Knight 2004). Croft (1999) believes that it would be an over simplification to label the wide range of complex psychological and hysiological factors that affect the way consumers interpret external stimuli as noise. Thus it could be argued that preferred sensory representation systems are not in themselves noise but ameans of cutting through noise.

\section{Sensory representation systems and marketing communications}

Although little research has been conducted into the validity of sensory representation systems (Sharpley 1984), research has been conducted into imagery and advertising that may offer insights into their relevance for advertising research. Grass and Wallace (1974) found that television commercials produced more favourable product attitudes and intentions than comparably derived print advertisements, probably due to the succession of visual images that television advertisements are able to use. Additionally, Lorayne and Lucas (1974) found that "bizarre images" aided recall.

Rossiter and Percy's (1978 and 1980) dual loop theory purports that visual content is "potentially as effective as verbal content in creating a favourable product attitude and persuading the consumer to purchase the product" (1980, p. 10). Some research has been undertaken into mental imagery, defined by Miller et al. (2000, p. 1) as "a mode of cognition involving the activation of perceptual knowledge stored in the long-term memory", resulting in an Advertisement-Evoked Mental Imagery Scale, consisting of 16 items including those that measure imagery relating to sight, sound, taste and smells. In this context, imagery is defined by Bone and Ellen (1992, p. 93) as "the representation of any sensory experience in working memory", however, as Skinner and Stephens (2003, p. 181) note, "even the word 'imagery' is from the language of the visual processor, and that not everyone internally processes external events by creating pictures, even when the external information is gained pictorially".

Two studies have been found that explore the link between sensory representation systems and marketing communications. Hinshaw-Orr and Murphy's (1990) research into responses to a range of television and radio advertisements did not support their hypothesis that consumers will recall advertising copy points expressed in their dominant representational system more frequently than points expressed in other representational systems. However, their work did support the hypotheses that consumers will rate an advertisement more favourably when it is expressed in their dominant NLP representational system, and that consumers will indicate higher intentions to purchase products promoted in advertisements which use their dominant representational systems.

Skinner and Stephens (2003) adopted a qualitative phenomenological approach to "examine the efficacy of television advertising in communicating to those within a target group by exploring the links between the advertisements that 'speak' to them most and their preferred representational systems" (p. 177). The two researchers, both trained NLP practitioners, showed respondents 15 purposively selected TV advertisements that appealed to different preferred sensory representational systems. Respondents expressed their reactions to the advertisements they felt had the most impact in "language relating to their preferred sensory representational systems" (Skinner and Stephens 2003, p. 177). Skinner and Stephens concluded that where respondents "with different representational systems chose the same advertisement as having the most effect, the reason for choice differed on a sensory basis" (2003, p. 188). The recommendation was that communicators should produce material that will appeal to an individual's preferred sensory representational system in order to engage and maintain that person's interest.

\section{Individual giving}

Historically, marketing was not seen as a traditional function of non profit organisations. However, many contemporary charities believe they are being "forced" to act more like private sector organisations in order to face the challenges of marketplace economies (Kinnell and MacDougall 1997). Increasingly, this means adopting strategic marketing practices in order to compete for customers, defined in a marketing communications context by Jenkinson et al., (2005, p. 79) as "donors, members and other parties who gain value from the support without being employed by the charity". As an example, Nichols (2003) notes the ever increasing number of competitors in the voluntary sector; in the USA pre 1900, 12 organisations solicited for funds, a number that had grown to $1,600,000$ by 2003 . With 169,249 active general charities in the UK market (UK Voluntary Sector Almanac 2006), attracting new donors to a cause and thereafter retaining donor loyalty is becoming crucial for survival. 
Industry figures (NCVO/CAF 2005) estimate individual giving in the UK in 2004/05 at $£ 8.2$ billion, and note that this source of income has increased during previous years where a decline year on year had been previously indicated. The survey does, however, note that 2005 was an exceptional year in terms of the number of charity appeals made of the public from the Asian Tsunami crisis, the famine in Dakur, the London Bombings, the hurricane in New Orleans and the Pakistan earthquake.

Moreover, a key finding of the Mintel Charities UK Survey (2006) that impacts on this research is that there was significant use of relatively new methods of giving i.e. giving over the telephone or the internet with two-fifths and three-fifths of donors, respectively, using these methods for the first time. In this context it is possible that advances in direct marketing communications and CRM software may facilitate better targeting of potential donors based upon less traditional segmentations variables, such as sensory representation systems (Skinner and Stephens 2003). The surveys mentioned above also note key demographic and geographic information of those giving to charities, but whilst this information will assist with the segmentation and targeting process, such information will only provide the breadth rather than the depth of the market place. Nichols (2003) believes that to be successful charities should look for clues found in segmentation for an understanding of the donor, their motivations and preferred means of communication.

\section{Methodology}

Similarly to the work of Skinner and Stephens (2003), this study is underpinned by interpretative phenomenological analysis in order to establish whether, in expressing their perceptions, respondents reveal their preferred sensory representational system through the language they use. Previous studies into NLP and the impact of advertisements (Hinshaw-Orr and Murphy 1990) have used student samples and have noted the limitation in this, both in terms of the homogeneity of the sample and that students are noted to produce different results compared to the rest of the population. In order to overcome this limitation, 21 adult respondents ranging in age from 22 to post-retirement were purposively chosen for our research (10 males and 11 females). Of these, 4 respondents are retired, 3 volunteer (including 2 of the 4 retired respondents), 4 work for charitable organisations, 3 respondents work in engineering, 3 in education, 2 in marketing roles, 2 in call centres, 1 in social work, and 1 in an administrative role.

Respondents were exposed to a range of charity marketing communications in small groups and their reactions were immediate. The groups were shown four television advertisements purposively chosen from the NSPCC, a well-known national charity (see Appendix 1 for details).

These advertisements were chosen because they were easy to access and, more importantly, all respondents were already familiar with the brand and the work of the charity, thus respondents were all starting from the same knowledge base. The use of the NSPCC advertisements in this research eliminated the need for the respondents to have to learn about the brand as they were all aware of the NSPCC prior to the research. The respondents, therefore, were able to concentrate on which of the four NSPCC advertisements they viewed had the greatest impact on them.

Given the nature of the research it was felt important for the researcher to use non-sensory language and to avoid leading the respondents in any way during the research process in order to eliminate any potential linguistic bias in responses. Respondents were therefore simply asked which advertisement had the most impact on them. Respondents were further asked what aspects of the advertisement they liked or disliked if it was necessary to stimulate further discussion in the groups.

\section{Findings}

As it is proposed that people express their preferred sensory representation system through the language they use, examples of the sensory language used by respondents have been italicised. Responses have been grouped under sensory representation system preferences and by advertisement, as there was no discernible difference in response based upon gender, age or occupation of respondents. Findings appear to show some link between a person's preferred sensory representation system, evidenced in the language they use, and their identification of the advertisement deemed by them to have had the most impact.

\section{Advertisement 1}

This advertisement was deemed to have had the most impact by all but one of the respondents identified by their sensory language as having a preference for internally visually processing an external event. 
The doll looked sinister and unsettling ... the expression on the doll's

face...no one else could see that it was a doll. The doll's face was very

pale. The way the doll kept looking down was powerful.

Other respondents commented on the "disturbing ... images" in this advertisement. "Number one was sinister and graphic".

Kinaesthetic processors did not evidence similar homogeneous responses as that found amongst visual processors. While five of these respondents deemed advertisement 1 to have the most impact, some appeared to find the advertisement, (in kinaesthetic language), difficult to grasp.

The first one I couldn't grasp at all

You were trying to figure out what it's all about

The trouble with the first one is I didn't cotton on directly what was going on at first ... I was struggling with the meaning of the first and so missed the point

\section{Advertisement 2}

Conversely, advertisement 2 was deemed to have had the most impact on kinaesthetic processors, being identified by 6 respondents.

The second advert was the most effective for me. I felt my heart rate go faster, I felt almost like I was there ... I thought that I might burst. I felt that something had been brewing for some time and this was the final straw.

One female respondent noted that "it goes through me and makes me cringe ... You knew exactly what was coming in the second ad - she was really losing it."

it angered me

the second advert with the mother and child had the most impact - she

flew off for no reason,

One female visual processor believed that "the father didn't look angry enough and the boy didn't look scared enough". Another visual processor believed that this advertisement "looked like a play". This respondent understood the need for strong images to be used in charity advertisements, commenting that "We are used to imagery, we are desensitised-most programmes after 8 pm have violence or difficult images."

However, responses were not as homogeneous amongst kinaesthetic processors as advertisement 1 was for visual processors. For one of the kinaesthetic processors, advertisement 2 "struck me least", and for the other, "it didn't work for me ... even though it made me go oooohhh."

\section{Advertisement 3}

This advertisement was only deemed to have the most impact by two of the respondents, both kinaesthetic processors noting that "the third was the most heart-tugging". However, another kinaesthetic processor commented that "I thought number three was very forgettable - no message was coming over. It wouldn't have touched any chords with me", and yet another that "I wasn't moved by advert three at all'

\section{Advertisement 4}

Only two respondents, kinaesthetic processors, deemed advertisement 4 as having the most impact on them.

Our findings therefore agree with previous studies that have evidenced a link between a person's preferred sensory representation system and the effect of marketing communications. 
However, not all three dominant representation systems were evident amongst our respondents. Skinner and Stephens (2003, p. 184) observe that "most people tend towards a preference for visual or kinaesthetic processing".

Our respondents were split between kinaesthetic $(n=15)$ and visual $(n=5)$ processors, although as an exploratory study the sample size is too small to make generalisations. One respondent was categorised by the researchers as evidencing what is referred to in NLP as synaesthesia, an inextricable linking between two representation systems - visual and kinaesthetic. In this case no one sensory representation system dominates.

\section{Discussion}

This study finds evidence that different advertisements appeal to different people and when asked for feedback, the language used by respondents was heavily sensory- based. Whether in a real-life situation the respondents would be moved to positive action, i.e. to make a donation, is another matter - this is where the other elements of the purchasing process come into play. The important finding is that individuals in this study have demonstrated that they have filtered information and this decision appears to be based on their preferred sensory representational systems.

While every respondent used expressions or words that reflect different senses, their use of predicates (words using sensory language) clearly indicated a dominant preferred sensory representational system. These results support similar positive findings from Skinner and Stephens (2003), and Hinshaw- Orr and Murphy (1990) who found that respondents were more inclined to positively identify with an advertisement that was presented in a matching sensory representation system to their own.

One interesting finding is that all but one of those with a strong visual preferred sensory representational system chose advertisement one as this seemed to have the most shocking and captivating image. Additionally, this advertisement was chosen as having the most impact by the respondent identified as having visual/kinaesthetic synaesthesia. Although this advertisement was also chosen by some of the kinaesthetic respondents, the images evoked very strong feelings in these respondents. This tends to concur with earlier studies into the effectiveness of strong imagery in advertising (Grass and Wallace 1974; Lorayne and Lucas 1974; Rossiter and Percy 1978 and 1980; Miller et al. 2000). Some respondents also mentioned their acceptance of charities' use of shocking and disturbing images (Fill 2002; Wilson and West 1995).

Whilst further large-scale research is needed, it would seem on the face of it that preferred sensory representational systems are noise in the communications process as recipients are filtering out information or not coding it in the way that the sender intended. However, the messages that appealed to the individual's preferred sensory representation system engaged the individual in a strong manner with all other messages discarded. This research therefore finds that individuals are selecting information on the basis of preferred sensory representational systems and thus this is a very important part of the perceptual selection process and therefore the purchasing process. While other factors such as income and the opinions of others, for example, will influence whether people are able to act on information, there is evidence to suggest that people are either tuned in or out to certain messages if they are biased towards certain sensory stimuli.

The potential impact of this in the voluntary sector is enormous. The sector spent $£ 59$ million in 2004 on main broadcast and press advertising (Mintel 2006) and this would not take into consideration all the other pieces of marketing communication that are used daily by every organisation such as locally produced leaflets, brochures, posters, presentation and other general communication materials. Producing campaigns that appeal to more than one preferred sensory representational system seems to provide an opportunity to achieve this goal, particularly for smaller local charities that may have equally small budgets for marketing communications. Charities are having to act more like businesses (Kinnell and MacDougall 1997), competing with others for customers, (Jenkinson et al. 2005) and practicing strategic marketing techniques such as segmentation, and target their communications mixes to these segments (Jenkinson et al. 2005). As their funds are limited it would appear to be important for the marketing academy to ensure that these organisations are offered insights into new methods of segmentation and targeting that could help ensure they maximise the return on each pound that is spent on their marketing communications. This study may 
also help provide some of the "clues" suggested by Nichols (2003) to help charities better understand their potential donors.

If organisations are able to use NLP to communicate with their target audiences more effectively, it may help provide a valid segmentation variable and an opportunity to build a meaningful relationship with a customer. While critics argue that the link between language and sensory representation systems is scientifically unproven (Sharpley 1984), proponents of NLP make it clear that it does not purport to be scientific. NLP "makes no commitment to theory, but rather has the status of a model -a set of procedures whose usefulness not truthfulness is to be the measure of its worth" (Dilts et al. 1980).

\section{References}

Ashok, S. and Santhakumar A. R. (2002), "NLP to promote TQM for effective implementation of ISO 9000", Managerial Auditing Journal, Vol. 17, No. 5, pp.261-265.

Bandler, R. and Grinder, J. (1975), The Structure of Magic, Palo Alto, CA: Science and Behaviour Books.

Bone, P. F. and Ellen, P. S. (1992), "The Generation and Consequences of Communication-evoked Imagery", Journal of Consumer Research, Vol. 19, No.1, June, pp. 93-104.

Carter, T. (2001), "Despite its detraction, NLP gains popularity”, ABA Journal, Vol. 87, No. 9, p. 63.

Croft, R. (1999), "Audience and Environment: Measurement and Media”. In: Kitchen, P. J. (ed.), Marketing Communications Principles and Practice, London: International Thomson Business Press.

Deetz, S. A. (1992), Democracy in the Age of Corporate Colonisation: Developments in the Communication and the Politics of Everyday Life, Albany, N.Y.: State University of New York Press.

Dilts, R. B., Grinder, J., Bandler, R. and Delozier, J. A (1980), Neuro Linguistic Programming Volume 1 - The Study of the Subjective Experience, Meta Publication.

Dilts, R. (1999), "What is NLP?". Available at: www.nlpu.com/whatnlp.htm [Accessed 5 January 2006].

Fill, C. (2002), Marketing Communications: Contexts, Strategies and Applications 3rd edition, Harlow: Pearson.

Grass, R. and Wallace, H. W. (1974), “Advertising Communication: Print Vs TV”, Journal of Advertising Research, Vol. 14, No. 5, pp. 19-23.

Hackley, G. and Kitchen, P. (1998), "IMC: A Consumer Psychological Perspective”, Marketing Intelligence \& Planning, Vol. 16, No. 3, pp. 229-235.

Hibbert, S. (2005), "Why Do People Give To Charity - and Why Don't Others? How Do We Encourage More Giving?", Charitable Giving and Donor Motivation. Mapping the Public Policy Landscape - Economic and Social Research Council Seminar Series, June 2005, Swindon, ESRC and NCVO.

Hinshaw-Orr, B. and Murphy, J. H. (1990), "Neuro-linguistic Programming Implications for Advertising and Copy Strategy". In: Stout, A. P. (ed.), Proceedings of the 1990 Conference of the American Academy of Advertising, American Academy of Marketing, pp. 111-116.

Jenkinson, A., Sain, B. and Bishop, K. (2005), "Optimising communications for charity brand management", International Journal of Nonprofit and Voluntary Sector Marketing, Vol. 10, No. 2, pp. 79-92.

Kinnell, M. and MacDougall, J. (1997), Marketing in the Not-for-Profit Sector, Oxford, Butterworth-Heinemann.

Knight, S. (2004), NLP at Work Neuro Linguistic Programming - The Difference That Makes a Difference in Business 2nd edition, London: Nicholas Brealey Publishing.

Lasn, K. (1999), Culture Jam: The Uncooling of America, New York: Eagle Brook.

Lorayne, H. and Lucas, J. (1974), The Memory Book, New York: Stein \& Day.

Mantovani, G. (1996), New Communication Environments: From Everyday to Virtual, London: Taylor and Francis.

Miller, D. W., Hadjimarcou, J. and Miciak, A. (2000), "A scale for measuring advertisement-evoked mental imagery", Journal of Marketing Communications, Vol. 6, No. 1, pp. 1-20.

Mintel (2006), Report on Charities UK - Advertising and Promotion, Mintel International Group Ltd. 
Nancarrow, C. and Penn, S. (1998), "Rapport in Telemarketing - Mirror, Mirror on the Call?", Marketing Intelligence \& Planning, Vol. 16, No. 1, p. 12.

NCVO/CAF, UK (2005), "Giving 2004/05 - Results of the 2004/05 Survey of Individual Charitable Giving in the UK". Available at: www.ncvo-vol.org.uk [Accessed 15th March 2006].

Nichols, J. E. (2003), "Repositioning Fundraising in the $21_{\text {st }}$ Century", International Journal of Nonprofit and Voluntary Sector Marketing, Vol. 9, No. 2, pp. 163-170.

O'Connor, J. and Prior, R. (1995), Successful Selling with NLP, Wellingborough: Thorsons.

Rees, J. (1995), “Calvin Klein makes offensive ads pay”, Marketing Week, 8th September 1995. In: Evans, M. and Moutinho, L. (eds.), (1999) Contemporary Issues in Marketing, London: Macmillan Press Ltd.

Rossiter, J. and Percy, L. (1978), "Visual Imaging Ability as a Mediator of Advertising Response", Advances in Consumer Research, Vol. 5, No. 1, pp. 621-629.

Rossiter, J. and Percy L. (1980), "Attitude Change through Visual Imagery in Advertising", Journal of Advertising, Vol. 9, No. 2, pp. 10-16.

Schramm W. A. (1971), "The nature of communication between humans". In: Schramm, W. A. and Roberts, D. F. (eds.), The Process and Effects of Mass Communication, Urbana, IL: University of Illinois Press, pp. 3-53.

Sharpley, C. F. (1984), "Predicate Matching in NLP: a review of research on the preferred representational system", Journal of Counselling Psychology, Vol. 31, No. 2, pp. 238-248.

Shimp, T. A. (2000), Advertising Promotion: Supplemental Aspects of Integrated Marketing Communication $5_{\text {th }}$ edition, London: Dryden.

Skinner, H. and Stephens, P. (2003), "Speaking The Same Language: The Relevance of Neuro-linguistic Programming to Effective Marketing Communications", Journal of Marketing Communications, Vol. 9, No. 3, pp. 177-192.

Stride, H. (2006), "An investigation into the values dimensions of branding: implications for the charity sector", International Journal of Nonprofit and Voluntary Sector Marketing, Vol. 11, No. 2, pp. 115-124.

UK Voluntary Sector Almanac (2006), published by National Council for Voluntary Organisations (NCVO) Publications.

Wilson, A. and West, C. (1981), "The marketing of unmentionables", Harvard Business Review, Vol. 51, JanuaryFebruary, pp. 91-102.

Wilson, A. and West, C. (1995), "Commentary: permissive marketing - the effects of the AIDS crisis on marketing practices and messages", Journal of Product and Brand Management, Vol. 4, No. 5, pp. 34-48.

Yemm, G. (2006), “Can NLP help or harm your business?”, Management Services, Vol. 50, No. 2, pp. 43-45.

\section{Appendix 1 NSPCC television advertisements}

Advertisement 1: An abused school-girl was represented by a dummy that was operated by a man who never left her side in the situations they were pictured at school, in the park and at home. The man always spoke for the "dummy".

Advertisement 2: A young boy proudly shows his mother a picture that he has drawn for her; the mother appears stressed and goes to lash out at the boy shouting that she doesn't want to look at his ridiculous pictures. A telephone ringing stops her. 241

Advertisement 3: A girl is pictured alone in a seemingly empty flat calling over and over for her mother.

Advertisement 4: A father is seen chasing his young son up the stairs; the boy shuts himself in the bedroom holding the door handle. The door handle is seen opening but a telephone rings and the man walks away. 


\section{About the authors and correspondence}

Suzanne Mainwaring is Director of the Noah's Ark Appeal (Children's Hospital for Wales) and a certified NLP Coach Practitioner.

Heather Skinner is a principal lecturer in marketing at the University of Glamorgan specialising in the marketing of services and other contemporary issues in marketing particularly for the non-profit and public sectors. She is also a neuro-linguistic programming practitioner with wide practical marketing experience.

Corresponding author: Mrs Heather Skinner, Glamorgan Business School, University of Glamorgan, Pontypridd, CF37 1DL, Wales, UK. $\mathrm{T}+44(0) 1443482820$

$\mathrm{F}+44(0) 1443482380$

E hskinner@glam.ac.uk 